\title{
The Application of Chinese Traditional Elements in Modern Visual Communication
}

\author{
Qianli Ma \\ Liaoning Institute of Technology, Jinzhou, Liaoning, 121000
}

Keywords: Chinese Traditional Elements, Modern Visual Communication, Application Area

\begin{abstract}
At present, the diversification of cultural development, the trend of globalization is a foregone conclusion, especially in the professional field of art design. Western developed countries gradually integrate into the design of our thinking, the designer for the traditional values and aesthetics also have a new understanding, "national is the world" is the design of nationalization and localization of the development of the slogan. How to understand the modern design and traditional elements of the collaborative development between China's designers becomes a new subject.
\end{abstract}

\section{Introduction}

The Chinese nation has a history of civilization for over five thousand years. In the long course of development, people use their wisdom and hardworking hands to create colorful material and spiritual civilization, including traditional cultural elements. Chinese traditional culture elements are very broad, including auspicious patterns, ink, calligraphy and paper cutting, these cultural elements have experienced a very long history of development, both in the form of expression or cultural connotations, can provide designers with rich art design The material and creative inspiration. They are integrated into the modern visual communication design, in the rich visual communication design works connotation, but also to the world to show China's profound and profound traditional culture, fully demonstrates the Chinese characteristics. Therefore, we should attach importance to the application of Chinese traditional cultural elements in visual communication design. But at this stage from the overall view of visual communication design, many works are lack of characteristics, imitation, plagiarism is serious, especially by the impact of Western design trends, designer design ideas into the misunderstanding, they blindly pursue new, discarded the nation Culture, resulting in the design of the work gradually lost the national character, lost the Chinese characteristics. In this case, how to combine the traditional Chinese cultural elements with the visual communication design, the formation of local characteristics with Chinese characteristics has become the majority of designers must study and explore the important issues. The following is a detailed analysis of this issue.

\section{Chinese Traditional Culture Elements and Visual Communication Design}

Traditional culture is shared by the Chinese nation, covering all kinds of different ideological and cultural content of the organic composition of the system, the Chinese people inherited from the objective existence of the cultural heritage, from which to draw out the representative things can be called traditional culture element. The Chinese nation has a long history, has a long history, after five thousand years of civilized development and cultural accumulation, the formation of a unique Chinese characteristics of the rich traditional cultural elements. These traditional cultural elements are unique cultural treasures of the Chinese nation, with unique characteristics. First, the subject matter is diverse. Chinese traditional culture elements all-inclusive, including Chinese calligraphy, seal seal, Chinese knot, Peking Opera, shadow, Oracle, paper cutting, auspicious patterns, Chinese painting, Chinese characters, in various forms, rich in content. Secondly, rich content. Chinese traditional cultural elements are mostly rich in life, philosophy, culture, rich connotations. Such as the traditional Chinese auspicious patterns: peony is rich and powerful, auspicious, happy, 
prosperous symbol, Lotus said, "out of the mud and not dye", there are clean gas and so on. Chinese traditional cultural elements are formed in the long river of history, the Chinese people in the transformation and creation of the world in the course of the practice of the essence of art, full of characteristics of the times. In recent years, many traditional cultural elements have been given a new life and value, into the visual communication design has become the first choice for the majority of designers.

Visual communication design is the expansion and extension of European and American print art design, the main use of visual symbols to pass a variety of information, which is the sender of information, to convey the object is the recipient of information. It can be said that all the design can be classified as a visual communication design, which covers a wide range, including logo design, advertising design, packaging design, print design, book design, display design, corporate image design, Viewers, the role of information transmission. Specifically, the designer mainly through the corresponding text, color and graphics to design, to highlight the characteristics, passed to people a variety of information, deepen the impression. With the development of society, the progress of science and technology, people no longer satisfied with the simple, single visual communication design, and hope that the work to achieve nationalization, personalization and humanity. In short, is to mobilize all the elements, to achieve the purpose of visual communication to the public to the visual psychological satisfaction. I believe that the "all elements" here include Chinese traditional cultural elements. This is the future development trend of visual communication design.

\section{Reflections on Chinese Elements}

To get out of a distinctive design of China's road, we should first view their unique design history and design culture. If it is possible to rely on Europe or the United States to solve the design of China's model, it is impossible. For the Germans, Bauhaus represented only the highest level of 90 years ago. And now the design of this era needs, but it is constantly innovative. China's design innovation, the source of inspiration seems to be more, which comes from the genetic chain of unique Chinese cultural elements.

Design, especially the visual communication design is actually to convey a culture. Culture is the reflection of human life, the record of activities, the accumulation of history, is the people's needs and requirements of life, ideals and aspirations, is the people's high spiritual life. It is the people to understand nature, thinking about themselves and is the human spirit to support the framework. Of course, what is produced by culture, whether it is literature, art or fashion, can not be with the natural language, but naturally not directly absorbed, few people have the realm and ability to directly from the natural nutrition, most People need to cook it cooked, we digest, this is culture. Nationalized design can be achieved extraordinary international exchanges and communication, and thus that their national cultural identity. Ye Jintian is the interpreter of the new Oriental aesthetics, he let the world understand the beauty of oriental culture and art. Ye Jintian through their own design to the world that the Chinese-style design how wonderful, unique, memorable, harmonious and interesting and full of the spirit of the times. Ye Jintian's creative methods are two kinds: one is to find the traditional very deep things, it is very different; the other is the traditional look of modern, of course, this is not simple. In this slowly accumulate a lot of things. Ye Jin-tian that: the future must have a traditional foundation, we must know where this thing comes from. In the West this is very clear, read the history of Western art know that each of them has a source, but in China a lot of things do not know the source, from the truth that do not go back, a lot of things can not do it directly and see it Then will have a problem, will escape their original things, no self-confidence. China's elements are numerous, once some unique features, textures or colors with Chinese modeling language and harmonious connection, and into the spirit of the times, it will produce easy to identify the Chinese-style design. Such as: calligraphy, seal, seal; Chinese knot, Beijing opera mask, shadow, martial arts; terracotta warriors, peach blossom, cloisonne, Chinese lacquerware, red lanterns; tea, ink and paper ink; Zuotao, Guanyin hand; instrument; dragon and phoenix pattern, Taotie pattern, back to grain, grain pattern, wishful pattern, clouds pattern; pottery, teapot, batik, 
porcelain, Dunhuang frescoes, tiger shoes, cheongsam, dumplings, hats, hats, hats, masts, lunks, lions Of the crown, the queen of the crown, so all sorts of, this unique national symbol of visualization into the design, will reach an extraordinary international exchanges and communication.

\section{Application of Chinese Traditional Cultural Elements in Visual Communication Design}

Traditional auspicious pattern is a traditional flower art in the garden of a flower, is the crystallization of the wisdom of our working people, carrying the context of the Chinese nation. There are plant patterns: plum, blue, bamboo, chrysanthemum, lotus, peony, etc., there are some geometric patterns, these auspicious patterns were given a Kind of national spirit, entrusted with their own production and life and the future of good blessing and wishes for the majority of designers to provide a wealth of creative material. In the design of modern visual communication, designers should use these traditional auspicious patterns according to the design theme, make full use of these traditional auspicious patterns, and transform, refine and innovate them into the visual communication design, so as to increase the meaning of the designed works and enrich its connotation , Highlighting the Chinese characteristics. Such as the 2008 Olympic Games in Beijing Olympic bid design, the designer selected the traditional Chinese auspicious patterns - plate long, the use of Chinese art-specific "and not like" between the freehand way, after art re-creation, just right to Chinese knot, the Olympic rings, running athletes three images closely together to show the spirit of the Olympic Games and Chinese style, to achieve a harmonious and harmonious realm. Another example is the packaging design of Shanxi Heng Fachun wine, the designer selected the traditional Chinese auspicious animal design - dragon and phoenix pattern, to the Han Dynasty portrait stone wine map to reflect its long history, and with the traditional blue and white porcelain pattern combination, with calligraphy name, Increased the identification of goods, and better convey the goods information, deepened the impression of consumers on the goods, brought back their desire to buy. In addition, the Phoenix TV station logo design of the traditional Chinese auspicious patterns - Phoenix, designers use paper cutting techniques, to take China's unique "hi meet" form of the structure, the combination of yin and yang, will be a phoenix a very dynamic Accommodated in a circle, embodies the Phoenix TV with the times, new business ideas and corporate culture. These works are the traditional auspicious patterns applied to the modern visual communication design success model, the majority of designers to learn from the essence, a reasonable reference to the useful part of them, and then design a better work.

Ink painting is a unique art of China, there is a kind of implicit beauty and artistic beauty, the accumulation of deep cultural connotation, embodies the Chinese people's national feelings. Implicit beauty is mainly reflected in the lines and blanks, mainly through the atmosphere it creates to experience and experience, is more emphasis on an inherent aesthetic way; artistic beauty depends on the artist on the color and line of control, Whether to achieve the painting without the beauty of the aesthetic effect. The use of ink and ink elements to the visual communication design, can make the traditional culture of color, texture modeling, etc. are reflected in the show a unique rhythm and charm at the same time, increase the visual convey the meaning of design works, highlighting national characteristics, Design of the art, the formation of a new art language. At this stage, China's visual communication design in many designers have used the ink elements, Jin Taiqiang, Shen Haopeng is one of the typical representative. Such as Jin Taiqiang's poster "free" series is full of a philosophy of life philosophy - ink column, the designer ink and elements of the expression of the subject at the same time arranged in the picture, the screen elements arranged in different styles, or "Sleep", "eat", "play" and other true meaning of life, giving a sense of lively and lively. Another example, the Shanghai graphic designer professional committee logo design, Shen Haopeng to ink in the traditional paper on the natural oozing paper as the background, the use of fine words theme, so that the two against each other, showing a special beauty. In short, the Chinese ink painting contains a wealth of design elements, designers must learn from the full nutrition, cleverly ink elements and visual communication design perfect combination, so as to enhance the visual communication design work mood. 


\section{Conclusion}

"Chinese traditional elements" is not simply a symbol of traditional cultural content and it is our modern visual communication design elements of the soul. China's traditional cultural elements and the Chinese nation's children's emotional blood is the same strain, so in the visual communication design process, the Chinese traditional elements appropriate to the design work, the traditional elements of China and modern fashion style of organic combination, This is the best way to convey the design of modern beauty and beauty of the times, but also to promote China's visual communication design to the world and an important way to sustainable development.

\section{References}

[1] Zhao Song. Analysis of visual communication design on the impact of modern life [J]. Arts and Technology, 2017 (01)

[2] Zhu Siyuan. Diversification and Personalization of Visual Communication Design [J]. Industrial Design, 2017 (03)

[3] Wang Xi. New media context of the visual communication design [J]. Tomorrow fashion, 2017 (12)

[4] Lin Shichu. Visual communication design of traditional painting art elements of the application of [J]. Tomorrow fashion, 2017 (12)

[5] Liu Huicheng. Analysis of the impact of digital media on visual communication design [J]. Takako (late), 2016 (12)

[6] Shazha Na. Visual communication design in the abstract graphics of the targeted refinement and performance [J]. Youth years, 2017 (09) 